\title{
Sementes de Senegalia polyphylla (Fabaceae) atacadas por bruquíneos podem ser viáveis?
}

\author{
Adriano Geraldo Fonseca1*(iD), Sebastião Lourenço de Assis Júnior ${ }^{1}$ (D) , Miranda Titon ${ }^{1}$ (D), Pedro Guilherme Lemos ${ }^{2}$ (D), \\ Evandro Luiz Mendonça Machado ${ }^{1}$ (D) \\ 'Universidade Federal dos Vales do Jequitinhonha e Mucuri, Campus JK, Rodovia MGT 367, km 583, n 5000, Alto da Jacuba, CEP 39100-000, Diamantina, MG, Brasil \\ 2Universidade Federal de Minas Gerais, Instituto de Ciências Agrárias, Avenida Universitária, n 1000, Bairro Universitário, CEP 39404-547, Montes Claros, MG, Brasil
}

*Autor correspondente:

adrianoengflor@gmail.com

Termos para indexação:

Dormência

Germinação das sementes

Stator

Index terms:

Dormancy

Seed germination

Stator

Histórico do artigo:

Recebido em 04/01/2018

Aprovado em 20/02/2020

Publicado em 25/11/2020

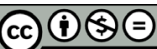

Espécies da família Fabaceae apresentam características fenológicas importantes, como folhas decíduas ou semidecíduas e produção de frutos, bastante influenciadas pelo estresse hídrico. Em sistemas fitofisionômicos, como nos grupos considerados monofiléticos, os padrões fenológicos são distintos, sugerindo que uma possível divergência seria a adaptação às condições típicas do Cerrado. Uma delas é a produção de frutos não carnosos, devido à influência dos ventos na dispersão de suas sementes, especialmente no período seco (Bulhão \& Figueiredo, 2002).
Algumas espécies nativas apresentam baixa germinação seminal, principalmente pela presença de tegumento impermeável e dormência primária. Estas características podem resultar no atraso da germinação e provocar desuniformidade das plântulas (Carrione et al., 2012). Há possibilidade, ainda, do dano causado por insetos à semente induzir a quebra de dormência, como estudado em sementes de Enterolobium contortisiliquum (Fabaceae) (Donato et al., 2010).

A espécie Senegalia polyphylla (DC.) Britton e Roose (Fabaceae) possui ampla distribuição na maioria dos 
domínios fitogeográficos brasileiros, como na Amazônia, Caatinga, Cerrado, Mata Atlântica e no Pantanal. É pioneira e possui síndrome de dispersão autocórica das sementes, as quais são ortodoxas e, possivelmente, apresentem dormência (Melo et al., 2010; Silva, 2011; Lemos \& Zappi, 2012; Mori, 2012).

A ordem Coleoptera possui 184 famílias e mais de 280.000 espécies. A maioria das espécies da subfamília Bruchinae (Chrysomelidae) ocorre na região neotropical e alimenta-se, predominantemente, de sementes de fabáceas (Borror \& Delong, 2011). As larvas desenvolvem-se e alimentam-se das sementes, podendo consumir parte do endosperma ou destruí-las completamente, incluindo o embrião. A determinação dos níveis de dano, taxas de predação e efeitos na germinação das sementes é importante, uma vez que pode fornecer estimativas da pressão de predação sofrida pelas plantas hospedeiras (Donato et al., 2010).

As sementes da maioria das espécies florestais brasileiras são danificadas por vários grupos de insetos, chegando, em algumas situações, a comprometer a sua propagação. A interação entre insetos sitófagos (devoradores de sementes) e as fabáceas foi observada em diversos trabalhos de levantamentos e quantificação dos danos (Almeida et al., 2006; Donato et al., 2010; Costa \& De Paula, 2012; Rodrigues, 2013).

Este trabalho teve como objetivo avaliar o efeito da predação de besouros bruquíneos na germinação e quebra de dormência de sementes de $S$. polyphylla comparadas a sementes sadias e outros processos de quebra de dormência.

Frutos de S. polyphylla foram coletados, diretamente de 10 matrizes em novembro de 2016, na região de São Gonçalo do Rio Preto, MG (18 $8^{\circ} 2^{\prime} 40,09^{\prime \prime}$ S, $43^{\circ} 23^{\prime} 22,76^{\prime \prime} \mathrm{W}, 840 \mathrm{~m}$ ). O clima, da região, de acordo com a classificação de Koppen é "Aw", definido como tropical, com temperatura média de $21,6{ }^{\circ} \mathrm{C}$ e pluviosidade de $1.216 \mathrm{~mm}$, concentrada no verão (Climate-Data.Org, 2018). Os frutos foram mantidos no Laboratório de Entomologia do Departamento de Engenharia Florestal da Universidade Federal dos Vales do Jequitinhonha e Mucuri, em Diamantina, MG. A exsicata foi depositada no Herbário Dendrológico Jeanine Felfili - HDJF da UFVJM, sob voucher 4706, para confirmação da espécie.

Quatrocentos frutos foram abertos e suas sementes contadas e classificadas em cinco categorias: indenes (sadias), chochas (malformadas ou abortadas), atacadas por Coleoptera, Lepidoptera ou infectadas por fungos. Os bruquíneos foram identificados na Universidade Federal do Paraná, PR.

Para determinação da perda de substrato pelo ataque do bruquíneo separou-se 100 sementes indenes e 100 atacadas por este inseto. O percentual de perda do material pelo ataque dos bruquíneos foi calculado pela divisão dos pesos das sementes atacadas pelas sadias. As sementes atacadas por lepidópteros não foram utilizadas nos testes, pois seus endospermas estavam completamente consumidos. Após a categorização das sementes, separou-se, aleatoriamente, 400 indenes e 100 danificadas pelo bruquíneo que, posteriormente, foram submetidas aos testes de germinação, constituindo os seguintes tratamentos, cada um com cem sementes:

- Tratamento 1: controle (sementes sadias);

- Tratamento 2: sementes sadias desinfestadas com hipoclorito de sódio 2,5\%;

- Tratamento 3: sementes sadias lixadas (lixa $n^{\circ}$ 100) e desinfestadas com hipoclorito de sódio $2,5 \%$;

- Tratamento 4: sementes sadias embebidas em água destilada por $24 \mathrm{~h}$ e desinfestadas com hipoclorito de sódio $2,5 \%$;

- Tratamento 5: sementes atacadas desinfestadas com hipoclorito de sódio $2,5 \%$.

Cada grupo de tratamento foi depositado em cinco linhas contendo 20 sementes cada, em caixas plásticas, tipo bandejas, com areia esterilizada e umidade controlada. As bandejas foram acondicionadas em sala climatizada, com temperatura variando de 25 a $28{ }^{\circ} \mathrm{C}$, umidade relativa do ar em torno de $70 \%$ e fotoperíodo de $12 \mathrm{~h}$. Os tratamentos com hipoclorito de sódio foram realizados em recipientes individualizados por tratamento, durante $10 \mathrm{~min}$. Posteriormente, as sementes foram lavadas, de acordo com o procedimento padrão das Regras de Análises de Sementes (Brasil, 2009).

A contagem das sementes germinadas foi feita a partir da emergência da plântula da superfície da areia. A contagem foi encerrada aos 10 dias após a montagem do experimento.

O delineamento experimental utilizado foi o inteiramente casualizado, com cinco repetições de 20 sementes. Os dados percentuais de germinação foram transformados em $\operatorname{arcsen} \sqrt{(x / 100)}$ e submetidos à análise de variância ao nível de 5\% de significância (Ramalho et al., 2005; Triola, 2008). Foi utilizado o 
software R, para análise dos dados, versão 3.3.1 (R Core Team, 2016), pacote ExpDes.pt. (Ferreira et al., 2013).

Cada fruto teve em média 6,1 sementes, das quais $1,6(26,21 \%)$ estavam atacadas por insetos ou fungos (Figura 1).

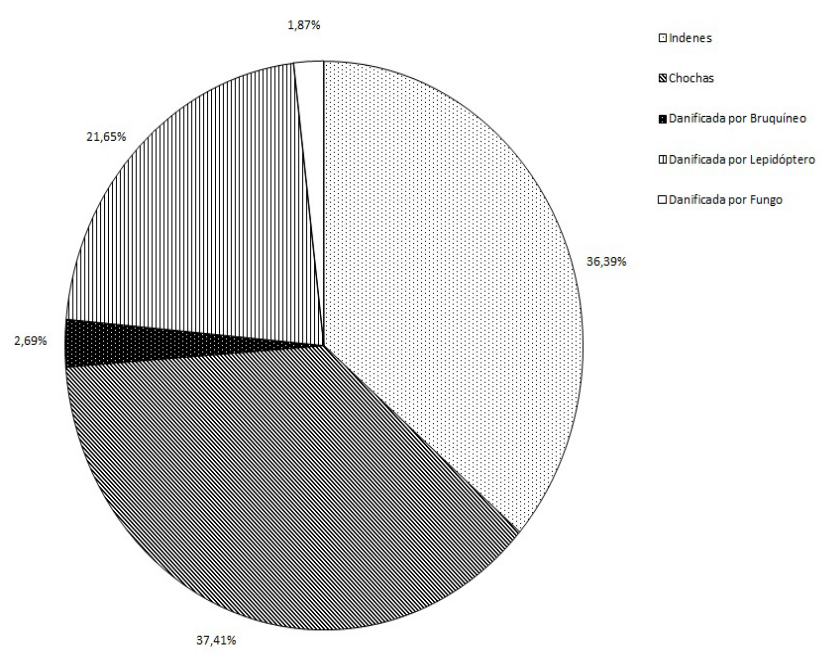

Figura 1. Percentual das sementes encontradas nos frutos de Senegalia polyphylla (DC.) Britton e Roose (Fabaceae) classificadas de acordo com sua condição fisiológica, Diamantina, MG.

Figure 1. Percentage of seeds from fruits of Senegalia polyphylla (DC.) Britton and Roose (Fabaceae) classified according to their physiological condition, Diamantina, Minas Gerais State, Brazil.

Os insetos espermatófagos associados a S. polyphylla foram identificados como Stator limbatus (Horn, 1873), S. vittatithorax (Pic, 1930), Stator sp. 1, Stator sp. 2 e Acanthoscelides clitellarius (Fåhraeus, 1839), todos Coleoptera, Chrysomelidae, Bruchinae. Os indivíduos da ordem Lepidoptera pertencem à família Pyralidae (Borror \& Delong, 2011).

O ataque dos bruquíneos foi responsável pelo consumo médio de $25,7 \%$ do peso das sementes, garantindo a menor taxa de germinação entre os tratamentos (Tabela 1).

O percentual de sementes chochas foi superior ao de indenes. Se somadas as perdas com predação, têm-se em torno de $63 \%$ de sementes consideradas inviáveis. A ocorrência de sementes chochas pode ser considerada uma perda energética considerável, pois pode inviabilizar sua germinação. Percentual maior de sementes chochas em relação às indenes também foi encontrado em Plathymenia reticula (Fabaceae) (Ribeiro et al., 2007).

Tabela 1. Germinação das sementes (\%) de Senegalia polyphylla (DC.) Britton e Roose (Fabaceae) em sala climatizada, a $28{ }^{\circ} \mathrm{C}$, Diamantina, $\mathrm{MG}$

Table 1. Seed germination (\%) of Senegalia polyphylla (DC.) Britton and Roose (Fabaceae) in acclimatized room, at $28^{\circ} \mathrm{C}$, Diamantina, Minas Gerais State, Brazil.

\begin{tabular}{lc}
\hline \multicolumn{1}{c}{ Tratamentos } & $\begin{array}{c}\text { Percentagem de } \\
\text { germinação }\end{array}$ \\
\hline Controle (T1) & $91 \mathrm{~b}$ \\
Sementes sadias (T2) & $41 \mathrm{c}$ \\
Sementes sadias e lixadas (T3) & $97 \mathrm{a}$ \\
Sementes sadias e embebidas em água (T4) & $36 \quad \mathrm{~d}$ \\
Sementes atacadas pelo bruquíneo (T5) & $27 \quad \mathrm{e}$ \\
*Médias com letras minúsculas na coluna diferiram estatisticamente pelo \\
teste de Tukey a 5\% de significância.
\end{tabular}

Estudos envolvendo interações inseto/planta já foram realizados em S. polyphylla na região de Cabo Frio, RJ. Nestes forami observadas a presença de outros insetos, inclusive com injúrias provocadas por galhadores (Maia $\&$ Souza, 2013). No entanto, não foi mencionado registro de predação de sementes.

O ataque dos bruquíneos foi responsável pelo consumo de pouco mais de 1/4 do endosperma das sementes, ao passo que os lepidópteros as destruiram completamente. Em estudo com Acacia mearnsii foi constatado que $S$. limbatus foi responsável pelo consumo de $60,4 \%$ do material das sementes atacadas, o que representava quase metade das sementes coletadas (Oliveira \& Costa, 2009). Os percentuais de predação aliados à baixa germinação de sementes podem se tornar um fator negativo e limitar a propagação de $S$. polyphylla.

Os melhores tratamentos para a quebra de dormência de sementes de $S$. polyphylla foram o que utilizou sementes sadias e lixadas e o controle. A época de coleta dos frutos pode ser um fator importante na determinação do percentual de germinação, como também na dormência, que ainda pode não ter se estabelecido com a maturação dos frutos. Isso pode ocorrer devido à condição fisiológica da semente e/ou do ambiente em que a planta mãe está presente, prevalecendo às condições consideradas ideais para sua germinação. Em ambientes com seca prolongada, pode ocorrer quiescência e não uma dormência propriamente dita. Arruda et al. (2015) coletaram os frutos de Acacia polyphylla na região norte do estado de Minas Gerais, no mesmo período deste trabalho (fim do período seco, em novembro), 
e encontraram baixa taxa de germinação, porém, com valores próximos ao do tratamento controle.

As sementes sadias embebidas em água e as atacadas pelo bruquíneo tiveram menor percentual de germinação (Tabela 1). A baixa taxa de germinação das sementes atacadas demonstra que a perda de substrato interferiu no metabolismo inicial da germinação. A troca de gases, processo normal em sementes no início da germinação, não é tão eficiente nesta condição. O rompimento do tegumento favorece uma respiração sem controle, além da exposição do endosperma a fatores externos. Isto pode comprometer a uniformidade do metabolismo de sementes que possuem faixas fotoblásticas mais estreitas (Labouriau, 1983).

De acordo com Mori (2012), a germinação das sementes de $S$. polyphylla com imersão por $2 \mathrm{~h}$ em água, à temperatura ambiente, foi de $73 \%$. Santos et al. (2015) demostraram que o processo de embebição do material seminal, realizado em areia como substrato, pode proporcionar uma melhor homogeneidade na germinação de sementes de pau-santo e pau-jacaré. Arruda et al. (2015), avaliando a germinação de sementes de Acacia polyphylla (sinonímia, Senegalia polyphylla) em gerbox e papel como substrato, obtiveram $100 \%$ de germinação com sementes lixadas e $20 \%$ com sementes atacadas por bruquíneo. Neste trabalho, obteve-se $27 \%$ de germinação com as sementes atacadas por bruquíneos (Tabela 1), resultado superior ao encontrado pelos autores anteriores.

A espécie em questão demonstrou maior potencial de germinação com o tratamento físico (lixa), devido ao maior contato da água com as paredes da semente e, consequentemente, maior embebição. A impermeabilidade tegumentar, comum em diversas espécies florestais é a principal característica da dormência de sementes. No entanto, existem vários métodos indicados para promover sua superação, considerando a espécie e o grau de dormência apresentado. Para uma boa germinação é necessário que o processo se inicie com a embebição das sementes em água e encerre com a protrusão da radícula pelo endosperma ou tegumento (Davide \& Silva, 2008).

Os resultados de germinação para sementes sadias tratadas em hipoclorito e sementes sadias tratadas em hipoclorito e embebidas em água foram menores que o controle. A absorção de água pelas células gera turgor em seu interior. A pressão de turgor é essencial para muitos processos fisiológicos, como o alongamento celular, trocas gasosas, entre outros. A perda de turgescência devido ao estresse hídrico provoca a redução da respiração, menor entrada de $\mathrm{O}_{2}$ e maior saída de $\mathrm{CO}_{2}$, interferindo em muitos processos metabólicos básicos, além de atuar na hidrólise do amido durante a germinação (Kerbauy, 2004; Taiz et al., 2017). A ação do hipoclorito foi nítida nestes dois tratamentos, podendo ter afetado a germinação das sementes sadias. O mesmo não ocorreu nas sementes lixadas e danificadas, já que houve ação de desinfecção ao contato direto com o endosperma desprotegido e oxidado. Este processo não interferiu na troca gasosa das sementes, pois o tegumento foi rompido pelo dano ou escarificação.

Em sementes de tamboril (E. contortisiliquum), foi encontrado um percentual de predação de $2,45 \%$ e estas sementes tiveram 5,0\% de germinação (Donato et al., 2010). No presente trabalho, S. polyphylla apresentou valor semelhante de predação $(2,69 \%)$ e baixo percentual de germinação $(27,0 \%)$, comparado aos outros tratamentos, porém superior ao tamboril. A predação causa grande perda de material de reserva das sementes e pode interferir na propagação da espécie. Mas, ainda assim, nem sempre impede totalmente sua capacidade de reprodução. Resta saber se os indivíduos provenientes de sementes predadas irão desenvolver plântulas e, posteriormente, árvores adultas com o mesmo vigor das provenientes de sementes sadias, garantindo a sucessão da espécie em seu ambiente natural.

\section{Conclusão}

Os maiores índices de germinação foram com sementes sadias lixadas e tratadas com hipoclorito de sódio.

$\mathrm{O}$ ataque de bruquíneos reduziu a germinação das sementes de Senegalia polyphylla e apresentou pior desempenho quando comparado a outros métodos de quebra de dormência. Ainda assim, algumas sementes danificadas pelo ataque desses insetos podem germinar.

\section{Agradecimentos}

Os autores agradecem à Coordenação de Aperfeiçoamento de Pessoal de Nível Superior - Brasil (CAPES), - Código de Financiamento 001 pelo apoio e à professora Dra. Cibele Ribeiro Costa, Universidade Federal do Paraná (UFPR) pela identificação dos bruquíneos. 


\section{Referências}

Almeida, C. I. M. et al. Fenologia e artrópodes de Copaifera langsdorffii Desf. no cerrado; Revista Brasileira de Plantas Medicinais, v. 8, n. 2, p. 64-70, 2006.

Arruda, D. M. et al. Germinação de sementes de três espécies de Fabaceae típicas de floresta estacional decidual. Revista Pesquisa Florestal Brasileira, v. 35, n. 82, p. 135-142, 2015. https://doi. org/10.4336/2015.pfb.35.82.672.

Borror, D. J. \& Delong, D. M. Introdução ao estudo dos insetos. São Paulo: E. Blucher, 2011. 809 p.

Brasil. Ministério da Agricultura, Pecuária e Abastecimento. Secretaria de Defesa Agropecuária. Regras para análise de sementes. Brasília, DF, 2009.

Bulhão, C. F. \& Figueiredo, P. S. Fenologia de leguminosas arbóreas em uma área do cerrado marginal no nordeste do Maranhão. Revista Brasileira de Botânica, v. 25, n. 3, p. 361-369, 2002. https://doi. org/10.1590/S0100-84042002000300012.

Carrione, R. M. et al. Tratamentos pré-germinativos em sementes de Plathymenia reticulata Benth. Revista Enciclopédia Biosfera, v. 8, n. 15, p. 1614-1621, 2012.

Climate-Data.Org. Clima de São Gonçalo do Rio Preto. Disponível em: <https://pt.climate-data.org/location/176041/>. Acesso em: 4 jun. 2018.

Costa, E. M. \& De Paula, R. C. A. L. Levantamento preliminar dos insetos associados às sementes de Albizia polycephala Benth em Vitória da Conquista - BA. Scientia Plena, v. 8, n. 4, p. 4730147305, 2012.

Davide, A. C. \& Silva, E. A. A. Produção de sementes e mudas de espécies florestais. Lavras: Ed. UFLA, 2008. 175 p.

Donato, D. B. et al. Dano de Caryedes sp. (COLEOPTERA; BRUCHIDAE) e seus reflexos na propagação de Enterolobium contortisiliquum (LEGUMINOSAE). Revista Floresta e Ambiente, v. 17, n. 2, p. 118-123, 2010. http://dx.doi.org/10.4322/ floram.2011.015.

Ferreira, E. B. et al. ExpDes.pt: experimental designs pacakge (portuguese). R package version 1.1.2. 2013. Disponível em: < https://mran.microsoft.com/snapshot/2014-12-29/web/ packages/ExpDes.pt/ExpDes.pt.pdf>. Acesso em: 2 mar. 2020.

Kerbauy, G. B. Fisiologia vegetal. Rio de Janeiro: Guanabara Koogan, 2004. 452 p.
Labouriau, L. G. A germinação das sementes. Washington: Secretaria Geral da Organização dos Estados Americanos, 1983. $174 \mathrm{p}$.

Lemos, J. R. \& Zappi, D. C. Distribuição geográfica mundial de plantas lenhosas da Estação Ecológica de Aiuaba, Ceará, Brasil. Revista Brasileira de Biociências, v. 10, n. 4, p. 446-456, 2012.

Maia, V. C. \& Souza, M. C. Insect gals of the xeric vegetation of Ilha do Cabo Frio (Arraial do Cabo, RJ, Brazil). Biota Neotropica, v. 13, n. 3, p. 278-288, 2013.

Melo, Y. et al. Morfologia de nectários em Leguminosae sensu lato em áreas de caatinga no Brasil. Acta Botânica Brasileira, v. 24, n. 4, p. 1034-1045, 2010.

Mori, E. S. Sementes florestais: guia para germinação de 100 espécies. São Paulo: Instituto Refloresta, 2012. 159 p.

Oliveira, L. S. \& Costa, E. C. C. Predação de sementes de Acacia mearnsii De Wild. (Fabaceae, Mimosoideae). Revista Biotemas, v. 22, n. 2, p. 39-44, 2009.

R Core Team. R: a language and environment for statistical computing. Vienna: R Foundation for Statistical Computing, 2016. Disponível em: <http://www.R-project.org > Acesso em: 02 mar. 2020.

Ramalho, M. A. P. et al. Experimentação em genética e melhoramento de plantas. 2. ed. Lavras: UFLA, 2005. 326 p.

Ribeiro, M. L. et al. Influência da predação de sementes na germinação de leguminosas (Fabaceae) no Cerrado. Revista Brasileira de Biociências, v. 5, n. 2, p. 279-281, 2007.

Rodrigues, L. M. S. Insetos predadores de sementes e suas relações com a qualidade e a morfologia de frutos e sementes. 2013. 117 f. Tese (Doutorado em Morfologia e Diversidade Vegetal) Universidade Estadual Paulista, Instituto de Biociências de Botucatu, Botucatu.

Santos, M. M. et al. Germinação e superação de dormência de sementes de espécies florestais. Revista Enciclopédia Biosfera, v. 11, n. 22, p. 1409-1417, 2015.

Silva, R. R. Leguminosae no Pantanal de Barão de Melgaço, Mato Grosso, Brasil. Biota Neotropica, v. 11, n. 4, p. 1-5, 2011.

Taiz, L. et al. Fisiologia e desenvolvimento vegetal. Porto Alegre: Artmed, 2017. 888 p.

Triola, M. F. Introdução a estatística. 10. ed. Rio de Janeiro: LTC, 2008. 696 p. 